\title{
HOMOAFETIVIDADE, PERFORMATIVIDADE DE GÊNERO E RELAÇÕES DE PODER: PERSPECTIVA QUEER EM O ATENEU1
}

\author{
HOMOAFETIVIDAD, PERFORMATIVIDAD DE GÉNERO Y RELACIONES DE \\ PODER: PERSPECTIVA QUEER EN LO "O ATENEU"
}

\section{HOMOAFFECTIVITY, GENDER PERFORMATIVITY AND POWER RELATIONS: QUEER PERSPECTIVE IN "O ATENEU"}

\author{
Márcia de Souza ${ }^{2}$ \\ https://orcid.org/0000-0003-0053-198X \\ Marcela Debona Laskoski ${ }^{3}$ \\ https://orcid.org/0000-0002-1649-8777 \\ Marília Hermes ${ }^{4}$ \\ https://orcid.org/0000-0003-1577-7843
}

Submissão: 06/07/2021 / Aceito: 12/07/2021/ Publicado: 30/09/2021.

\begin{abstract}
RESUMO
A teoria literária assinala a literatura como ponto nuclear da área das humanidades, tendo em vista a potencialidade epistemológica dos textos literários. Neste caso, trata-se de um estudo bibliográfico que analisa a obra $O$ Ateneu de Raul Pompeia, publicada no Brasil em 1888, período reconhecido na linearidade da história da literatura como Realismo. Com os subsídios da Teoria Queer, pesquisamos as questões de poder, a performatividade de gênero e as consequências dessas características no comportamento das personagens centrais ao longo da narrativa. Percebemos que o comportamento e a personalidade delas não ocorrem gratuitamente, possuem intenção de crítica política, mas, no processo, uma relação profunda entre performatividade de gênero, sexualidade e poder é revelada. As reflexões em torno da obra apontam como o ambiente do internato impõe modos de pensar e agir à comunidade escolar. A obra escapa aos preceitos literários da época e evidencia comportamentos sociais singulares, como é o caso do tensionamento da narrativa em torno da homoafetividade e performance de gênero.
\end{abstract}

\footnotetext{
${ }^{1}$ A pesquisa bibliográfica foi realizada nos componentes curriculares "Literatura Brasileira: do Simbolismo ao Modernismo" e Teoria da Literatura: a crítica literária, ministradas pela Professora Márcia de Souza, no curso de Licenciatura em Letras: Português e Inglês e Respectivas Literaturas, da Universidade Comunitária da Região de Chapecó, em 2020.

${ }^{2}$ Doutora em Literatura pela Universidade Federal de Santa Catarina. Professora vinculada ao Curso de Letras da Unochapecó. Chapecó, Santa Catarina, Brasil, marcias@unochapeco.edu.br

${ }^{3}$ Graduada em Produção Audiovisual, graduanda do curso de Licenciatura em Letras: Português e Inglês e Respectivas Literaturas, da Universidade Comunitária da Região de Chapecó - UNOCHAPECÓ. Chapecó, Santa Catarina, Brasil, marcelalaskoski@unochapeco.edu.br

${ }^{4}$ Graduada em Produção Audiovisual, graduanda do curso de Licenciatura em Letras: Português e Inglês e Respectivas Literaturas, da Universidade Comunitária da Região de Chapecó - UNOCHAPECÓ. Chapecó, Santa Catarina, Brasil, imabramovitch@gmail.com
} 
Palavras-chave: Homoafetividade. Heterossexualidade compulsória. Performatividade de gênero. Relações de poder. Crítica literária.

\title{
RESUMEN
}

La teoríaliterariaseñala a la literatura como unpunto nuclear enel área de las humanidades, en vista de lapotencialidad epistemológica de los textos literarios. Se trata de unestudio bibliográfico que analizala obra "O Ateneu" de Raul Pompeia, publicada en Brasil en 1888, período reconocidoenlalinealidad de lahistoria de la literatura como Realismo. Con las subvenciones de lateoríaqueer, buscamos por lascuestiones de poder, laperformatividad de género y las consecuencias de estas características enelcomportamiento de la protagonista a lo largo de lanarración. Nos dimoscuenta de que sucomportamiento y personalidad no se producen de forma gratuita, tienenintención de crítica política, pero, enelproceso, se revela una profunda relación entre laperformatividad de género, lasexualidad $\mathrm{y}$ el poder. Las reflexiones en torno al trabajoindicancómoel entorno del internado impone formas de pensar y actuar a lacomunidad escolar. La obra escapa a lospreceptosliterarios de la época y pone de relievecomportamientossociales singulares, como es el caso de latensión de lanarraciónen torno a laactuaciónhomoafectiva y de género.

Palabras clave: Homoafectividad. Heterosexualidadcompulsoria. Performatividad de género. Relaciones de poder. Críticaliteraria.

\begin{abstract}
The literary theory points out literature as the core point of human studies due to the epistemological strength of literary texts. The current work refers to a bibliographical study that analyses the work O Ateneu, written by Raul Pompeia, published in 1888 in Brazil, a period known as Realism in the timeline of literary history. With subvention from the Queer Theory, we researched the power issues, gender performativity and their consequences in behaviors from the main characters along with the narrative. We were able to notice the fact that their behavior and personalities are not for granted, they present the intent of making a political statement however, during the narrative a deeper correlation between gender performativity, sexuality and power dynamics is revealed. The reflections around the book shows us the environment of the boarding school imposes its way of thinking and acting to their school community. Pompeia's work falls a little of to the literary principles of the period and highlights social and singular behaviors, such as the tension of the storyline around homosexuality and gender performance.
\end{abstract}

Keywords: Homoafectivity. Compulsory heterosexuality. Gender performativity. Power relations. Literarycriticism.

\section{INTRODUÇÃO}

A obra $O$ Ateneu $^{5}$, de Raul Pompéia, causou polêmicas desde o lançamento. Publicado em um período marcado por acirrados enfrentamentos políticos no meio intelectual, no qual, de acordo

\footnotetext{
${ }^{5}$ Usaremos o termo $O$ Ateneu, em itálico, para nos referir a obra e o Ateneu, sem itálico, quando mencionarmos o colégio ou internato.
} 
com Roberto Ventura (apud MISKOLCI; BALIEIRO, 2011), tais polêmicas eram a tradução de disputas simbólicas a respeito de um ideal de nação formado juntamente com a consolidação do regime republicano. A obra mostra, de forma ácida, punitiva e sarcástica, a vida no interior de um internato, e usa diversos artifícios para produzir críticas sociais. A combinação de caráter e masculinidade é um deles.

As experiências e os sentimentos do protagonista Sérgio são o fio condutor da história, em que relações afetivas e de poder ganham centralidade e exibem a violência escancarada no ambiente opressor do Ateneu. Dois aspectos chamam a atenção pela intensidade com que são apresentados: a homoafetividade e as relações de poder exercidas pelos integrantes dessa "microsociedade". Outro aspecto interessa-nos por motivo oposto, é uma questão percebida de forma mais sutil e requer olhar atento: as relações que homoafetividade e poder apresentam com a performatividade de gênero. A partir disso, propomos uma análise com perspectiva Queer da obra O Ateneu, para reconhecer quais mecanismos de controle e poder permeiam a narrativa e a que eles servem, além de compreender a construção dos sujeitos a partir dos papéis performativos de gênero. Levamos em consideração a definição de Teoria Queer descrita por Culler, ou seja, como um modo de pensar contemporâneo capaz de dialogar com aspectos sociais periféricos: “[...] usa o marginal - o que foi posto de lado como perverso, além dos limites, radicalmente outro - para analisar a construção cultural do centro: normatividade heterossexual". (CULLER, p. 126, 1999).

O Ateneu foi publicado em 1888, escrito por Raul Pompéia, um sujeito "revoltado" nas palavras de Mário de Andrade (1974). Basta uma leitura atenciosa para perceber o tom crítico e sarcástico que a obra apresenta, tom esse que, de acordo com Mário de Andrade é punitivo e carrega a intenção de vingança contra a vida nos internatos. O romance mostra a vida no ambiente disciplinador e opressivo do Ateneu ${ }^{6}$ e coloca em primeiro plano as experiências e sentimentos do protagonista Sérgio. As personagens do romance são insensíveis e perversos, apenas o pai de Sérgio é poupado na história, contra o qual não existem vestígios de mágoa. $\mathrm{O}$ antagonismo dos vínculos afetivos entre os personagens ganham destaque no decorrer da leitura. Por um lado as manifestações de homoafetividade são amplamente praticadas na escola e, por outro, existe a conduta moral vigente, para a qual a homoafetividade era considerada desonrosa e passível de punição. Paralelo a isso, a violência é apresentada com a mesma intensidade. Existe uma relação velada entre o

\footnotetext{
${ }^{6}$ A obra narra as experiências de Sérgio, no colégio interno Ateneu, instituição de ensino para crianças de famílias endinheiradas, localizado na cidade do Rio de Janeiro. A identidade do internato é usada também como nome da obra O Ateneu.
} 
comportamento dos personagens, papéis performativos de gênero e as relações de poder existentes no interior do internato. Sexualidade e erotismo não passaram despercebidos na sociedade do fim do século XIX, tampouco nas subsequentes. Essa foi, inclusive, a motivação do suicídio de Pompeia, visto que, como aponta Mário de Andrade (1974), o livro possui caráter autobiográfico. É importante dizer que o período de publicação do livro, o fin de siècle, foi marcado por disputa política acirrada no meio intelectual, acerca do ideal de nação que se formava com o regime republicano. Roberto Ventura pontua essas disputas entre homens da elite brasileira, e

[...] a associação entre nação e masculinidade vinculava-se à preocupação com o caráter modelar destes homens, de sua suposta missão viril de representar e encarnar os ideais políticos que se confundiam com rígidos valores morais. Neste sistema de valores normativos, a adesão aos ideais era premiada no mesmo grau em que era temida e perseguida qualquer suspeita de dissidência. (VENTURA apud MISKOLCI; BALIEIRO, 2011, p. 2).

A ideia de nação como território e os traços de um sistema regulamentar para a obediência social, podem ser correlacionados aos comportamentos e caráter dos personagens da narrativa em análise, os quais possuem intenção de crítica política, pertinente ao momento de publicação da obra. Entretanto, nesse movimento, Pompeia delineia uma nova perspectiva para a concepção "da masculinidade e das relações afetivo-sexuais impostas aos homens brancos da elite nacional". (MISKOLCI; BALIEIRO, 2011, p.2). Silviano Santiago diz que, devido à complexidade de $O$ Ateneu, uma interpretação unilateral é insuficiente, pois "cada análise do romance permitia uma outra interpretação, oposta ou lateral, igualmente válida e justa. Todos os críticos iam tendo razão, sem a ter inteiramente" (SANTIAGO, 1978, p. 68 apud SOUZA, 2019, p.102). Reiteramos a heterogeneidade da obra, a postura crítica dos personagens, e propusemos esta análise com a perspectiva Queer acerca dos papéis performativos de gênero, afetividade e relações de poder presentes na obra. Para tanto, apresentaremos alguns conceitos necessáriosà análise. Em nossa primeira seção discutiremos performatividade de gênero, heterossexualidade compulsória e relações de poder.

\section{Performatividade de GÊNERO}

Durante muito tempo o gênero teve sua concepção amparada pelo sexo biológico, sendo eles tratados como sinônimos. Apresentaremos a abordagem genealogia da ontologia de gênero, da filósofa Judith Butler, (2008), a qual aponta o caráter performativo do gênero. De acordo com essa 
perspectiva, o gênero nos é atribuído no nascimento, e com tal atribuição nascem diversas expectativas sobre como esse corpo comporta-se na sociedade e que papéis assume.

Entende-se por ontologia de gênero a busca por uma essência que determine o indivíduo "homem" e o indivíduo "mulher" como tal. Judith Butler(2008) apresentou a abordagem genealogia da ontologia de gênero para destacar a presença das estruturas de poder que agem na manutenção da ontologia de "mulher" e "homem". A autora Patrícia Rosa, ao falar sobre a abordagem de Butler, diz que a genealogia da ontologia de gênero aponta o caráter de "construção performativa do gênero, que busca a internalização e reificação de normas heterossexuais" (ROSA, 2012, p.47).

Butler (2008) firma-se em leituras de Foucault para basear essa abordagem. Para ela, Foucault apresenta o corpo como "uma superfície onde história e cultura se inscrevem. O corpo, segundo essa abordagem, perde seu valor e é significado pelas estruturas de poder que se inscrevem no seu aparecer" (ROSA, 2012, p.48). O corpo possui materialidade que se molda a partir das expectativas existentes para cada "tipo" de corpo, em determinado momento/lugar. A materialidade molda os corpos, e também gestos/ações, a partir do que deve ser compreendido por "homem" e “mulher”. Para ela, a forma como o corpo é visto, utilizado e ritualizado está intrinsecamente ligado à cultura.

Rosa (2012) aponta ainda a necessidade de refletir acerca da ameaça que paira sobre todos os indivíduos no que diz respeito à fuga da figura determinada cultural e socialmente para os papéis de "mulher" e "homem". De acordo com a autora, tendo o corpo um local pré-determinado, a quebra dessa demarcação representa uma ameaça à ordem social. Tal ameaça é respondida na forma de sanções, como isolamento social ou ira divina. É pertinente acrescentar à observação da autora que a humilhação, a desumanização e a violência - física ou moral - fazem parte dessa ameaça.

As normas sociais a respeito da masculinidade e feminilidade agem como um mecanismo de internalização dos conceitos de "homem" e "mulher", determinando ações, gestos, trejeitos, tom de voz, etc., fazendo com que "homens" ajam de determinada forma, e "mulheres" de outra. Esse é o ponto de partida para o próximo conceito.

\section{HeTEROSSEXUALIDAdE COMPULSÓRIA}

AdrienneRich (2010) problematiza as consequências da obrigatoriedade da sexualidade heteronormativa. Os questionamentos, a princípio, partem da existência lésbica, e o conceito apresentado aqui estende o pensamento de Rich a todas as demais manifestações afetivas e sexuais 
divergentes da normatividade. Os métodos são apresentados a partir da vivência de corpos lésbicos, e é importante dizer que a vivência da mulher lésbica difere da vivência dos demais indivíduos queer. Há uma violência estrutural relacionada primeiramente à condição de mulher em uma sociedade patriarcal, e à condição de indivíduo de sexualidade desviante da normatividade. Reiteramos que todos os indivíduosqueersofrem com violências provenientes da ordem social, mas de formas distintas e de acordo com o local ocupado socialmente.

Para a autora, a heterossexualidade é uma instituição que reforça o poder masculino dentro de uma sociedade estruturada pelo patriarcado. Ela apresenta alguns métodos de opressão, dos quais apresentaremos apenas os que dizem respeito à sexualidade divergente, e não necessariamente às categorias "mulher"/“lésbica":

- Negação da sexualidade através de punição (inclusive morte) devido a adultério ou a simples manifestação sexual/afetiva divergente da normatividade;

- Forçar a heterossexualidade por meio de estupros corretivos, agressão física, incesto, socialização heterossexual, romantização e idealização da heterossexualidade na arte, na literatura, na mídia, na propaganda etc.;

- Confinamento e exclusão social por meio do mecanismo do medo, como estupros, assédios, violência física, moral e simbólica, restrição à ocupação de empregos e espaços institucionais;

- Objetificação dos corpos divergentes e fetichização ao apresentar tais indivíduos como objetos de satisfação sexual;

- Restrição da criatividade através do que a autora apresenta como uma "caça às bruxas", validando as representações culturais heteronormativas em detrimento das desviantes, tornando os valores culturais um mero reflexo da heteronormatividade, apagamento de tradições não heterocentradas.

Rich afirma que confrontamos a manutenção de "forças que abarcam desde a brutalidade física até o controle da consciência" (RICH, 2010, p.25). A heterossexualidade compulsória é um discurso produzido e padronizado que invisibiliza e pune indivíduos desviantes da normatividade e garante a manutenção da dominação heteronormativa. Aspectos concernentes às relações de poder que envolvem essa predominância serão abordados no próximo tópico.

\section{RELAÇÕES DE PODER}


A palavra poder advém do indo-europeu poti, utilizada para designar a chefia de grupos sociais. Na derivação para o grego pótis tem sentido de marido e despotés, a princípio com a significação de senhor, chefe da casa, passou a ser usado para nomear tiranos. No latim vulgar, potere significa posse no latim clássico, a contração de potis esse, "ser capaz", "autoridade”. A etimologia da palavra indica uma ação que exprime persuasão, controle, força. O Dicionário de Termos Literários ${ }^{7}$ define o poder como algo intrínseco das relações humanas. Para o controle das condutas individuais ele efetiva-se de diferentes formas e é reconhecido na história com base em inúmeros fundamentos. No âmbito da produção literária, o poder tem função importante, basta que observemos os recursos utilizados para a difusão e normatização dos conteúdos “que ora nos surgem censurados e banidos por um qualquer organismo governamental, ora segregados pelo crivo editorial ou pela crítica jornalística, ora integrados na grande tradição literária" (LOPES, 2009, on-line) . $^{8}$

Em um dicionário comum da língua portuguesa o significado de poder é apreciado em 18 sinônimos, com destaque para: 'ter a faculdade ou o direito, de: poder determinar algo'; “dispor de força ou autoridade'; 'direito de deliberar, agir ou mandar'. (FERREIRA, 2001, p. 577 apud FERREIRINHA; RAITZ, 2010, p.370, grifos das autoras).

A palavra poder está sempre associada à autoridade. Michel Foucault, (1984), dedicou-se seis anos, de 1970 a 1976, ao estudo de três áreas: poder, direito e verdade. No ensaio Soberania e Disciplina, o autor coloca em discussão as relações hierárquicas de poder presentes na sociedade e aponta fatores que as levam à manutenção. Para o filósofo, o poder não está em uma instituição, nem é configurado como algo que se cede como contratos, mas reprime e produz efeitos de saber e verdade.

Quero dizer que em uma sociedade como a nossa, mas no fundo em qualquer sociedade, existem relações de poder múltiplas que atravessam, caracterizam e constituem o corpo social e que estas relações de poder não podem se dissociar, se estabelecer nem funcionar sem uma produção, uma acumulação, uma circulação e um funcionamento do discurso. (FOUCAULT, 1984, p. 101).

O filósofo define o poder como um conjunto de recursos de natureza psicológica, material, e/ou econômica que os indivíduos colocam a serviço de uma autoridade, a fim de manter uma ordem. O mecanismo do poder pode ser ilustrado por um triângulo e, em cada um dos vértices encontramse poder, direito e verdade. Esses três componentes podem ser ilustrados da seguinte forma: o rei representa o centro, a concentração do poder; o súdito representa a periferia para onde o poder se

\footnotetext{
${ }^{7}$ O Dicionário de Termos Literários (on-line), organizado por Carlos Ceia, Faculdade de Ciências Sociais e Humanas, da Universidade Nova de Lisboa, Portugal, está disponível em: https://edtl.fcsh.unl.pt/. Acesso em: junho de 2021.

8 Definição de poder elaborada por António Lopes, 2009, para o Dicionário de Termos Literários, disponível em: https://edtl.fcsh.unl.pt/encyclopedia/poder/. Março de 2021.
} 
desencadeia; e o próprio poder, a força material que se concentra e desencadeia. "Se há o rei, há também os súditos, se há leis que operam, há também os que a determinam e os que devem obediência" (FERREIRINHA; RAITZ, 2010, p.370).

\begin{abstract}
Foucault discorre que as relações de poder postas, seja pelas instituições, escolas, prisões, quartéis, foram marcadas pela disciplina: É pela disciplina que as relações de poder se tornam mais facilmente observáveis, pois é por meio da disciplina que estabelecem as relações: opressor-oprimido, mandante-mandatário, persuasivo-persuadido, e tantas quantas forem as relações que exprimam comando e comandados. (FOUCAULT, 2008 apud FERREIRINHA; RAITZ, 2010, p.371).
\end{abstract}

Os conceitos apresentados podem ser correlacionados à análise de $O$ Ateneu. Desde o início da narrativa, Sérgio é apresentado à estrutura social organizada no ambiente do internato. Na chegada do protagonista ao local é alertado sobre as relações "perversas" entre os alunos.

\begin{abstract}
Aí vão as carinhas sonsas, generosa mocidade... Uns perversos! Têm mais pecados na consciência que um confessor no ouvido; uma mentira em cada dente, um vício em cada polegada de pele. Fiem-se neles. São servis, traidores, brutais, adulões. Vão juntos. Pensase que são amigos... Sócios de bandalheira! Fuja deles, fuja deles. Cheiram a corrupção, empestam de longe. Corja de hipócritas! Imorais! Cada dia de vida tem-lhes vergonha da véspera. (POMPEIA, 1996, p. 14).
\end{abstract}

Percebemos a existência de "modelos" comportamentais diferentes e inclusive divergentes para cada situação. As condutas podem ser chamadas de "oficiais", moldadas por normas de ordem moral e dos princípios da tradição cristã. O comportamento oficial segue estrutura hierárquica que contempla a todos os envolvidos - o diretor Aristarco no topo, a família do diretor, logo abaixo professores, funcionários e alunos do Ateneu. Entre os alunos havia uma subdivisão oficial: os vigilantes estavam acima dos alunos comuns.

Por amor da regularidade da organização militar, repartiam-se as três centenas de alunos em grupos de trinta, sob o direto comando de um decurião ou vigilante. Os vigilantes eram escolhidos por seleção de aristocracia, asseverava Aristarco. (POMPEIA, 1996, p. 19).

Nesse modelo comportamental, percebemos a estrutura de poder conforme discutidas por Foucault: ele age como um conjunto de normas explícitas, de ordem psicológica e moral, e está a serviço da ordem comum: manter os ditos "bons costumes" provenientes da criação cristã, a hierarquia e a disciplina. Com a ilustração do funcionamento do poder em triângulo, podemos dizer que ele age da ponta do triângulo para baixo, ou seja, do rei para o súdito, em que o rei representa quem está acima na ordem hierárquica oficial do Ateneu. A adesão a tais comportamentos e valores era premiada pelos meios oficiais. Logo no início da narrativa a figura nobre do diretor do Ateneu é destacada: "Não só as condecorações gritavam-lhe do peito como uma couraça de grilos: Ateneu! 
Ateneu! Aristarco, todo era um anúncio. Os gestos, calmos, soberanos, eram de um rei - o autocrata excelso dos silabários”. (POMPEIA, 1993, p. 24).

Entretanto, paralelo ao modelo comportamental oficial, havia uma segunda norma, desviante, corrupta, que funcionava no internato de forma velada. Apesar de atingir a todos, a relação entre estudantes é a mais evidente. A dinâmica dessas normas mudava a todo o momento, de acordo com os envolvidos, o contexto e quem possui mais poder. Essa cadeia hierárquica difere da oficial, pois não depende dela. Podemos perceber relações hierárquicas entre os alunos nos seguintes meios: por idade, os mais velhos possuíam mais poder sobre os mais novos, por performance de gênero, os considerados "efeminados" estavam abaixo dos considerados "másculos", por força física, os mais fortes ficavam acima dos mais fracos, e por desempenho escolar, os alunos com melhores notas eram premiados, enquanto os alunos com baixo desempenho passavam por situações de humilhação. Entre alunos e superiores, podemos perceber que existem relações hierárquicas baseadas em questões econômicas, os privilégios ficavam reservados aos alunos de famílias mais ricas.

\begin{abstract}
Acreditei algum tempo que a minha impunidade era um caso especial do afamado sistema das punições morais e que Aristarco delegara ao abutre da minha consciência o encargo da sua justiça e desafronta. Hoje penso diversamente: não valia a pena perder de uma vez dois pagadores prontos, só pela futilidade de uma ocorrência, desagradável, não se duvida, mas sem testemunhas. O caso morreu em segredo de discrição, encontrando-nos eu e o diretor num conchavo bilateral de reserva, como se nada houvesse. (POMPEIA, 1996, p. 80).
\end{abstract}

As relações baseavam-se no poder conferido de acordo com a posição de classe social dos indivíduos. Exemplo disso é quando Sérgio confessa se interessar na amizade de Sanches, pelos privilégios que o amigo poderia lhe conferir. Ao longo da leitura, percebemos que a relação de Sanches com Sérgio também possuía interesses, visto que Sérgio passa a performar o papel efeminado na relação.

Sanches era também vigilante. Estes oficiais inferiores da milícia da casa faziam-se tiranetes por delegação da suprema ditadura. Armados de sabres de pau com guardas de couro, tomavam a sério a investidura do mando e eram em geral de uma ferocidade adorável. Os sabres puniam sumariamente as infrações da disciplina na forma: duas palavras ao cerrafila, perna frouxa, desvio notável do alinhamento. Regime siberiano, como se vê, do que resultava que os vigilantes eram altamente conceituados. No caso particular da nossa fortuita aproximação, não podia deixar de influir consideravelmente a bela importância colegial do vigilante Sanches. (POMPEIA, 1996, p. 19).

Isso nos impele a olhar para a dinâmica de relacionamento entre os personagens e podemos observar a analogia aos relacionamentos heteronormativos. Há uma necessidade não mencionada de performar certas estruturas de gênero, na ausência de figuras femininas, os homens mais jovens e/ou frágeis são submetidos ao papel feminino nas relações. Relembramos o conceito de heterossexualidade compulsória definido por AdrienneRich (2010): a heterossexualidade é uma 
instituição que reforça o poder masculino em uma sociedade patriarcal, e as forças que mantêm tal obrigatoriedade vão desde a brutalidade física até o controle de consciência. O Ateneu era um ambiente que regia as relações interpessoais através de mecanismos de poder. A afetividade configurava-se em um desses mecanismos. É necessário também apontar o caráter performativo do gênero, em que o corpo é significado pelas estruturas de poder que o moldam. A ideia de efeminação era amplamente repudiada e ao mesmo tempo secretamente aceita entre os alunos. Embora o papel do efeminado fosse temido, era assumido quando necessário. Como diz Butler, (2008), a forma como o corpo é visto, utilizado e ritualizado está profundamente ligado à cultura. As normas sociais, definidas no contexto do Ateneu através do poder, determinavam a necessidade da performatividade da feminilidade ou masculinidade do indivíduo em diferentes momentos, lugares e relações. "Os gênios fazem aqui dois sexos como se fosse uma escola mista. Os rapazes tímidos, ingênuos, sem sangue, são brandamente impelidos para o sexo da fraqueza; são dominados, festejados, pervertidos como meninas ao desamparo" (POMPEIA, 1996, p. 14).

O protagonista vive, durante toda a narrativa, um conflito com sua própria percepção do papel que exibe no ambiente escolar. A partir do momento em que é apresentado à figura do homem efeminado de maneira agressivamente pejorativa, Sérgio passa a sentir repulsa pelas características ditas femininas em si mesmo, pois elas significam inferioridade em relação ao parceiro dominante. Via de regra, o papel do efeminado não é escolhido, é uma condição para a qual o indivíduo é forçado a desempenhar. Entretanto, há os que escolhem ou os que aparentam se sentir confortáveis com tal posição, como é o caso de Cândido. Essas são figuras dignas de escárnio no ambiente do internato, a exemplo do mesmo personagem que depois de descoberto o romance com outro colega de classe foi humilhado publicamente por Aristarco.

\footnotetext{
'Tenho a alma triste. Senhores! A imoralidade entrou nesta casa! Recusei-me a dar crédito, rendi-me à evidência...' Com todo o vigor tenebroso dos quadros trágicos, historiou-nos uma aventura brejeira. Uma carta cômica e um encontro marcado no Jardim. 'Ah! mas nada me escapa... tenho cem olhos. Se são capazes, iludam-me! Está em meu poder um papel, monstruoso corpo de delito! assinado por um nome de mulher! Há mulheres no Ateneu, meus senhores!' Era uma carta do Cândido, assinada Cândida. [...] 'Estes são os acólitos da vergonha, os co-réus do silêncio!' Cândido e Tourinho, braço dobrado contra os olhos, espreitavam-se a furto, confortando-se na identidade da desgraça, como Francesca e Paolo no inferno. Prostrados os doze rapazes perante Aristarco, na passagem alongada entre as cabeceiras das mesas, parecia aquilo um ritual desconhecido de noivado: a espera da bênção para o casal à frente. Em vez da bênção chovia a cólera. ' ... Esquecem pais e irmãos, o futuro que os espera, e a vigilância inelutável de Deus!... Na face estanhada não lhes pegou o beijo santo das mães... caiu-lhes a vergonha como um esmalte postiço... Deformada a fisionomia, abatida a dignidade, agravam ainda a natureza; esquecem as leis sagradas do respeito à individualidade humana... E encontram colegas assaz perversos, que os favorecem, calando a reprovação, furtando-se a encaminhar a vingança da moralidade e a obra restauradora da justiça!...'. (POMPEIA, 1996, p. 78-81, grifos do autor).
} 
Desde a chegada no Ateneu, Sérgio sentiu-se compelido a esconder e moldar os traços do próprio caráter. O menino encontrava-se longe de casa pela primeira vez, e em contato com o mundo externo via-se diante de uma série de novas regras a respeito do ser, estar e agir, sentindo-se sozinho e assustado pela falta de amparo. A fraqueza dele, apesar de normal para uma criança da sua idade, era tratada como sinal de inferioridade por ser uma característica "efeminada".

As percepções de Sérgio mudaram depois do acidente durante a natação. Os conselhos de Rabelo 9 são ofuscados pelo medo dos alunos mais velhos, pois "tudo ameaça os indefesos". A insegurança causada pelo quase afogamento juntamente com as dificuldades acadêmicas formam uma atração pelo colega Sanches. A relação entre os dois não é baseada em afeto e sim nos interesses mútuos, como apresentado anteriormente, e num sentimento de obrigação pela parte de Sérgio, pois Sanchez o havia salvo no episódio do afogamento, mesmo que, internamente, o menino questionasse as intenções de Sanches e o considerasse responsável pelo acidente, assim estabelecendo uma ligação traumática entre os dois. Esse não foi o resultado de um ciclo de abusos, mas uma ligação baseada no medo de futuros possíveis abusos. A relação acabou em violência física entre os dois. Após o término do relacionamento com Sanches, o protagonista tenta isolar-se do ambiente escolar. Seu comportamento demonstra uma tentativa de compensação, passando da reação inicial com atitudes "agressivas" ao total "isolamento", somado a um intenso interesse pela religião. O menino busca na religião um refúgio ou pelo menos algo que faça algum sentido em meio a seus conflitos. Nessa passagem destaca-se a presença de Ribas, personagem que atrai o desejo de Sérgio, não de maneira afetiva, porém de admiração pela bela voz do rapaz, característica vista como feminina em passagens anteriores é verbalizada como algo que ele gostaria de possuir.

A fragilidade de Ribas, o qual é descrito como um menino feio, frágil e com aparência quase cadavérica, mas com uma voz divina, encantava Sérgio. Apesar de possuir traços delicados, condenados de maneira velada no Ateneu, ele era muito estimado por Aristarco, figura de poder central na escola, possivelmente por Ribas ser um jovem reservado, ao contrário de Cândido, por exemplo, o qual atraía atenções por sua personalidade extravagante.

O personagem Franco, desde o início cativou a Sérgio; franzino parecia uma espécie de mártir. O protagonista viu-o pela primeira vez de joelhos, em punição, posição na qual era constantemente encontrado e frequentemente citado no temido "livro de notas". O fascínio de Sérgio pelo colega pode ser pelo menino representar transgressão, porém, não uma contravenção que

\footnotetext{
${ }^{9}$ Rabelo era reconhecido no internato como aluno "sério e honrado". Discípulo do professor Mânlio, ele foi indicado para ser o protetor/orientador de Sérgio.
} 
assombra, mas uma ideia nova de transgressão e desvio moral que aparentemente não causam em Franco nenhum tipo de vergonha e arrependimento. Encantado por tal comportamento, Sérgio inicia um relacionamento com Franco, mas a amizade acaba devido ao incidente dos cacos de vidro na piscina, incidente que também separou Sérgio do caminho com a espiritualidade.

Apesar das relações afetivas se construírem entre pessoas do sexo masculino, elas não configuram necessariamente indivíduos homoafetivos, visto que as relações são moldadas por mecanismos de poder, seguindo um padrão heteronormativo em que um indivíduo performa a masculinidade, e outro a feminilidade. Mesmo assim, identificamos indícios de homoafetividade em Sérgio. O personagem vive constante busca, muitas vezes inconsciente, por afeto e o procura sempre em figuras masculinas. Sérgio teve vários parceiros e sempre se encontrava em uma posição de admiração, dedicação e contemplação, características comuns à paixão. O desejo se manifesta nas sutilezas:

Confusamente ocorria-me a lembrança do meu papelzinho de namorada faz-de-conta, e eu levava a seriedade cênica a ponto de galanteá-lo, ocupando-me com o laço da gravata dele, com a mecha de cabelo que lhe fazia cócega aos olhos; soprava-lhe ao ouvido segredos indistintos para vê-lo rir, desesperado de não perceber. [...] Deu-me um botão de flor de laranjeira que tinham remetido. (POMPEIA, 1996, p. 79).

A abertura do capítulo IX dedica uma página inteira para falar dos relacionamentos de Sérgio, todos chamados "amizade", mas a narrativa ocupa-se especialmente à descrição de Egbert e consideramos essa relação a primeira realmente afetiva de Sérgio. O protagonista demonstrava imenso carinho e devoção ao companheiro, nesse trecho, a narrativa flui de forma leve, porém intensa. Ao descrever a relação, o protagonista cita as situações mais cotidianas vivenciadas em companhia do amigo e utiliza uma ternura que descreve os momentos como mágicos. Com Egbert, Sérgio teve contato com emoções mais simples e menos abusivas, como o ciúme e o medo da perda. A descrição da abertura do capítulo IX é profunda, poética e contemplativa. Fica evidente que tudo o atraía em Egbert, e observá-lo gerava prazer.

\footnotetext{
Tinha o rosto irregular, parecia-me formoso. De origem inglesa, tinha os cabelos castanhos entremeados de louro, uma alteração exótica na pronúncia, olhos azuis de estrias cinzentas, oblíquos, pálpebras negligentes, quase a fechar, que se rasgavam, entretanto, a momentos de conversa, em desenho gracioso e largo. Vizinhos ao dormitório, eu, deitado, esperava que ele dormisse para vê-lo dormir e acordava mais cedo para vê-lo acordar. Tudo que nos pertencia, era comum. Eu por mim positivamente adorava-o e o julgava perfeito. Era elegante, destro, trabalhador, generoso. Eu admirava-o, desde o coração, até a cor da pele e à correção das formas. Nadava como as toninhas. A água azul fugia-lhe diante em marulho, ou subia-lhe aos ombros banhando de um lustre de marfim polido a brancura do corpo. (POMPEIA, 1996, p. 84).
} 
A presença de D. Ema também chama a atenção. Egbert é convidado para um jantar na casa de Aristarco e convida Sérgio para acompanhá-lo. No jantar, Sérgio reencontra D. Ema, a esposa do diretor, por quem o rapaz se vê seduzido. A descrição na sequência é curiosa, pois ao contrário da descrição apaixonada de Egbert, a apresentação de D. Ema é breve, pausada, sensorial, doméstica e materna, em oposição às descrições de Egbert, longas, detalhadas e estéticas. O relato do perfil de D. Ema assemelha-se a uma lista, com atributos supostamente atraentes em mulheres.

Miragem sedutora de branco, fartos cabelos negros colhidos para o alto com infinita graça, uma rosa nos cabelos, vermelha como são vermelhos os lábios e os corações, vermelha como um grito de triunfo. Nada mais. Ramalhetes à mesa, um caldo ardente, e sempre a obsessão adorável do branco e a rosa vermelha. [...] Serviam-me alguns pratos, muitas carícias; eu devorava as carícias; Não ousava erguer a vista. (POMPEIA, 1996, p. 88).

Essa experiência brevíssima operou uma transformação em Sérgio, e soa muito mais como uma conveniência do que um sentimento de fato. É como um rito de passagem - Sérgio encontrou uma mulher que cumpriu os "requisitos de interesse" com base na ideia amplamente reafirmada das expectativas para uma companheira. Todos os outros relacionamentos de Sérgio, nas diversas formas e manifestações, foram muito bem motivados com diversas páginas de descrições dos rapazes, como aparências, trejeitos, aptidões, atividades nas quais se envolviam. Todo esse conteúdo afirmava a relação e a contextualizava. É possível compreender os caminhos por onde o sentimento de Sérgio passa. Entretanto, nesse episódio com D. Ema, isso não fica evidente, como se ser mulher por si afirmasse justificativa para o desejo do rapaz e refletisse a obrigatoriedade moral da relação heteronormativa.

De volta ao Ateneu, senti-me grande. Crescia-me o peito indefinivelmente, como se me estivesse a fazer homem por dilatação. Sentia-me elevado, vinte anos de estatura, um milagre. Examinei então os sapatos, a ver se haviam crescido os calcanhares. Nenhum dos sintomas estranhos constatei. Mas uma coisa apenas: olhava agora para Egbert como para uma recordação e para o dia de ontem. (POMPEIA, 1996, p. 88).

A citação encerra o capítulo IX e como um rito de passagem, a masculinidade de Sérgio é recompensada. Algo interessante a se observar nessa altura do texto é que D. Ema passa a ocupar o lugar de Egbert. No capítulo seguinte, o narrador demonstra prazer em chamá-la simplesmente Ema. “(era agradável suprimir o D.), pequenina como uma abelha de ouro, vibrante e incerta. Sonhei: ela sentada na cama, eu no verniz do chão, de joelhos” (POMPEIA, 1993, p. 170). 


\section{CONSIDERAÇÕES}

A obra $O$ Ateneu abriu margem a polêmicas, prendeu o interesse de críticos e leitores dada a característica de transgressão moral, profundidade psicológica dos personagens, tom sarcástico de crítica política e caráter autobiográfico. No período de publicação da obra, fim do século XIX, era comum a associação entre masculinidade e caráter modelar e, portanto, compreendemos o comportamento e a personalidade dos personagens como instrumento de crítica política usado por Raul Pompeia com certo grau de sarcasmo. Entretanto, a interpretação unilateral da obra não é suficiente, olhamos para ela com a perspectiva queer para assinalar aspectos relevantes à conduta de alguns dos personagens, mas outras perspectivas podem ser consideradas. De acordo com (SOUZA, 2019, p. 126), "Pompeia não se sujeitou aos regimes disciplinares e sua produção literária não pode ser hermeticamente rotulável, mas, pelo contrário, oferecer campos de tensões a serem investigados".

Compreendemos a intenção sarcástica de crítica instaurada por Pompeia ao registrar manifestações de personalidade divergentes da normatividade e apresentar novas formas de relação afetiva, utilizando-se de conceitos provenientes da moral cristã e tradicional. Com mostras de relações homoafetivas, o autor não abandonou a heteronormatividade inerente às relações, tornandoas réplicas de relacionamentos heterossexuais em que um indivíduo "homem" performa a masculinidade e o outro a feminilidade. Esses relacionamentos são fruto de uma estrutura social baseada em poder, hierarquia e disciplina. Dividimos a hierarquia entre "oficial" e "imoral, obscena”. Ambas contemplam os indivíduos da obra, a primeira reconhecida oficialmente, premia aqueles que a aderem e a segunda como micro-sociedade estabelecida visivelmente entre os alunos. Podemos observar como os personagens adultos abusam do poder perante os alunos mais jovens, considerados frágeis e "inferiores", para os quais afeto era moeda de troca a fim de proteção contra abusos praticados no ambiente do internato. Encontramos aqui uma afetividade ilusória baseada no medo, que torna o protagonista confuso em relação ao desenvolvimento da própria noção de afetividade.

No universo do Ateneu, existe a necessidade de reproduzir estruturas de gênero, os rapazes mais jovens e fracos são vinculados a papéis tipicamente femininos. Apesar das relações afetuosas construírem-se entre indivíduos do sexo masculino, elas não configuram homoafetividade, visto que as relações eram moldadas por mecanismos de poder, seguindo um padrão heteronormativo. Ainda assim, identificamos indícios velados de homoafetividade, como os apresentados neste estudo. 
Entretanto, a organização da sociedade heteronormativa impele os indivíduos a buscarem relações heterocentradas.

\section{REFERÊNCIAS}

ANDRADE, Mário de. Aspectos da literatura brasileira. $5^{\circ}$ edição. São Paulo, Martins, 1974.

BUTLER, J. Problemas de Gênero: feminismo e subversão da identidade. $2^{\text {a }}$ Edição.

Tradução de Renato Aguiar. Rio de Janeiro: Civilização Brasileira, 2008.

CULLER, Jonathan. Teoria literária: uma introdução. Trad. Sandra Vasconcelos. São Paulo: Beca Produções Culturais Ltda, 1999.

FERREIRINHA, Isabella Maria Nunes; RAITZ, Tânia Regina. As Relações de Poder em Michel Foucault: Reflexões Teóricas. Rio de Janeiro. 2010.

FIGUEIREDO, Fernando de. A pedagogia do sexo em o ateneu: o dispositivo da sexualidade da "fina flor da mocidade brasileira", Universidade Federal de São Carlos, 2009.

FOUCAULT, Michel. Microfísica do poder. $4^{\mathrm{a}}$ ed. Org. e trad. Roberto Machado. Rio de Janeiro: Edições Graal, 1984.

MISKOLCI, Richard; BALIEIRO, Fernando de Figueiredo. O Drama Público de Raul Pompeia Sexualidade e política no Brasil finissecular. Revista Brasileira de Ciências Sociais, vol. 26, nº 75. São Paulo. 2011.

POMPEIA, Raul. O Ateneu. 16a ed. São Paulo: Ática, 1996 (Bom Livro).

POMPEIA, Raul. O Ateneu. Apuração do texto com o original e introdução por Therezinha Bartholo, ilustração do autor. Rio de Janeiro: Francisco Alves, 1993.

ROSA, Patrícia. Gênero: Performativo ou Ontológico? Peri - Revista de Filosofia, v.04, no01. Florianópolis. 2012.

RICH, Adrienne. Heterossexualidade compulsória e existência lésbica. Revista Bagoas, $\mathrm{n}^{\circ} 05$. 2010.

SOUZA, Márcia de. O Ateneu: "edifício alegórico". 145 f. Tese (Doutorado em Literatura) Universidade Federal de Santa Catarina, Florianópolis, 2019. 